\title{
Is there gender discrimination in the marketplace of short-time rental?:
}

\author{
the case of Xiaozhu.com \\ Xinting Bian ${ }^{*}$, Hongcheng Wang \\ Nanjing University of Science and Technology, China \\ *Corresponding author: Xinting Bian, bianxinting@163.com
}

\begin{abstract}
In the past few years, the model of P2P was introduced to the area of short-time house rental. Online marketplaces often contain information about products and the people who sell the products. In this paper, we test for gender discrimination against landlords in the online rental marketplace Xiaozhu.com. According to our research, landladies charge approximately $10.47 \%$ more than landlords for the equivalent rental. These effects are robust when all information visible in the Xiaozhu marketplace is controlled. These findings highlight the popularity of discrimination in online marketplaces, suggesting an unintended consequence of a seemingly-routine mechanism for building trust.
\end{abstract}

KEY WORDS: P2P; Short-time house rental; Price; Gender discrimination; Xiaozhu.com

\section{Introduction}

\subsection{Research background and significance}

With the development of the Internet, online housing short-time rental transactions become more and more popular. Xiaozhu.com is a well-known short-term rental online trading platform built in 2011. In order to facilitate transactions, Xiaozhu provides a stable evaluation system for users. One of the most important features of Xiaozhu's evaluation system is to ask the hosts to upload personal information, including their photographs, age and constellation, to facilitate the trust between tenants and hosts, which may potentially cause the tenants' discrimination to the hosts.

The study of factors to short rent price and discussing whether the hosts' gender will have an impact on the prices on online platform will help to discuss whether the web site's disclosure of personal information and photographs of the hosts will cause discriminatory behavior and put pressure on the platform to force them to take measures to reduce discrimination. 


\subsection{Research methods and ideas}

The main research object of this paper is the short-time rental information of Beijing published on the November 4, 2015 on Xiaozhu.com (http://www.xiaozhu.com/), and the data set covers short rental housing price information, housing quality information and the hosts' personal information.

This paper does an empirical study on the price of housing short rent and the gender of the landlords. First, the descriptive statistics and graphs will give us intuitive feelings. Then, an empirical study of housing prices and a series of variables reflecting house quality and hosts' sex are conducted. Finally, the relationship between the sex of the hosts and the price of the house is discussed.

\section{Current status of foreign and domestic research}

The gap between domestic and foreign research on the topic is relatively large. Foreign scholars have begun to use quantitative methods to study, but domestic research are mostly about the P2P concept and development description, which are mostly the qualitative research.

\subsection{Status of foreign research}

Devin G. Pope and Justin R. Sydnor (2009) ${ }^{1}$ found that black borrowers were less likely to receive loans than whites in the same credit. There is discrimination against the elderly and overweight and women and people with military backgrounds are preferred. But the difference may be caused by factors behind the skin. Benjamin Edelman and Michael Luca $(2014)^{2}$ found that for the same rental housing, non-black landlords charge about $12 \%$ more than the black landlords. Airbnb requires users to upload personal photos, which makes the appearance of discrimination more serious.

\subsection{Status of domestic research}

Yi Fan (2014) ${ }^{3}$ introduces the concept and development history of online short rent. Ling Chao and Zhang Zan (2014) hold that China's economic development and population conditions have their own characteristics. We cannot completely copy the foreign development model. Pan Yong (2006) ${ }^{4}$ holds that e-commerce market has more serious information asymmetry. Actions should be taken to avoid the price discrimination in Internet market: (1) to make full use of the advantages of online technology to improve the efficiency of information dissemination; (2) to definite malicious price discrimination in online 
transactions in legal regulation; (3) to establish a stable trust mechanism to promote the mutual trust between the network market participants.

\section{Empirical analysis}

\subsection{Data}

The data set contains a total of 1691 pieces of data about the information on each room of Beijing on November 4, 2015, each including the price of the house, the characteristics of the house and the characteristics of the landlord (the specific indicators can be seen in Table 1).

Table 1 - Main data indicators

\begin{tabular}{|l|l|l|l|l|l|l|}
\hline Main indicators & \multicolumn{5}{|l|}{ Specific indicators } \\
\hline Price & Price per day & Price per day per person & \\
\hline Quality & Favorable rate & Cleanness & Match & Cost-effective & Safety & Traffic \\
\hline Landlord & Name & Gender & Age & constellation & & \\
\hline
\end{tabular}

We downloaded all the public photos from the web pages. Encode the landlords according to the gender: 0-photos are not available, 1-male, 2-female, 3-family, 4-unclear, 5-family with kid(s). Encode the landlords according to sharing the house or not: 1-full rent, 0-other (including single room rental, bed rental, sofa rental, etc.).

The quality of the house cannot be checked by us for the time and geographical constraints, so we use the tenants' scores after living as quantitative information.

\subsection{Empirical research}

\subsubsection{Determinants of prices on Xiaozhu}

Table 2 shows the descriptive statistics of the price. Figure 1 shows the distribution with a maximum of 3500 yuan and a minimum of 35 yuan. Over $90 \%$ of the price distributes in 0 499 yuan, 8\% of the price distributes in 500 999 yuan. Very few houses charge over 1000 yuan. The average price is 276 yuan. We have 588 landlords and 788 landladies. Landladies are more likely to charge more.

Table 2 - Descriptive statistics

\begin{tabular}{l|lllll}
\hline Variable & Valid & Mean & Std. & Min & Max \\
\hline Landlords & 588 & 242.7347 & 169.6086 & 35 & 2298 \\
\hline Landladies & 788 & 271.9467 & 221.1607 & 42 & 2600 \\
\hline Landlords \& landladies & 1691 & 276.3276 & 234.8286 & 35 & 3500 \\
\hline
\end{tabular}




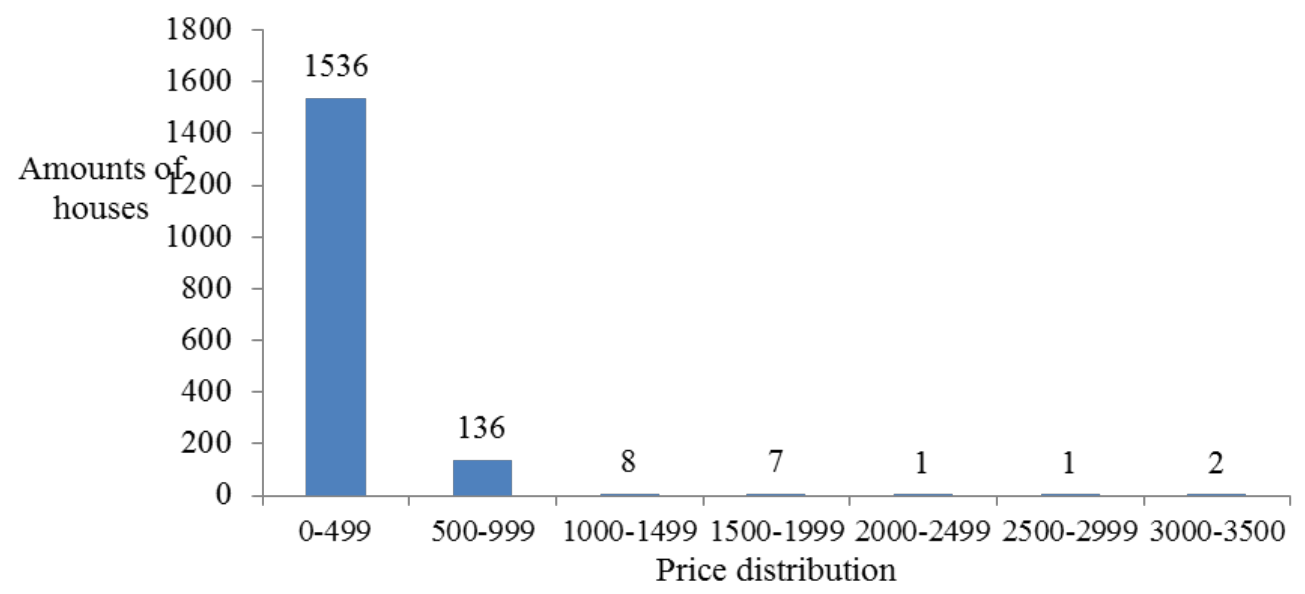

Figure 1 - Housing price distribution in Beijing area on Xiaozhu

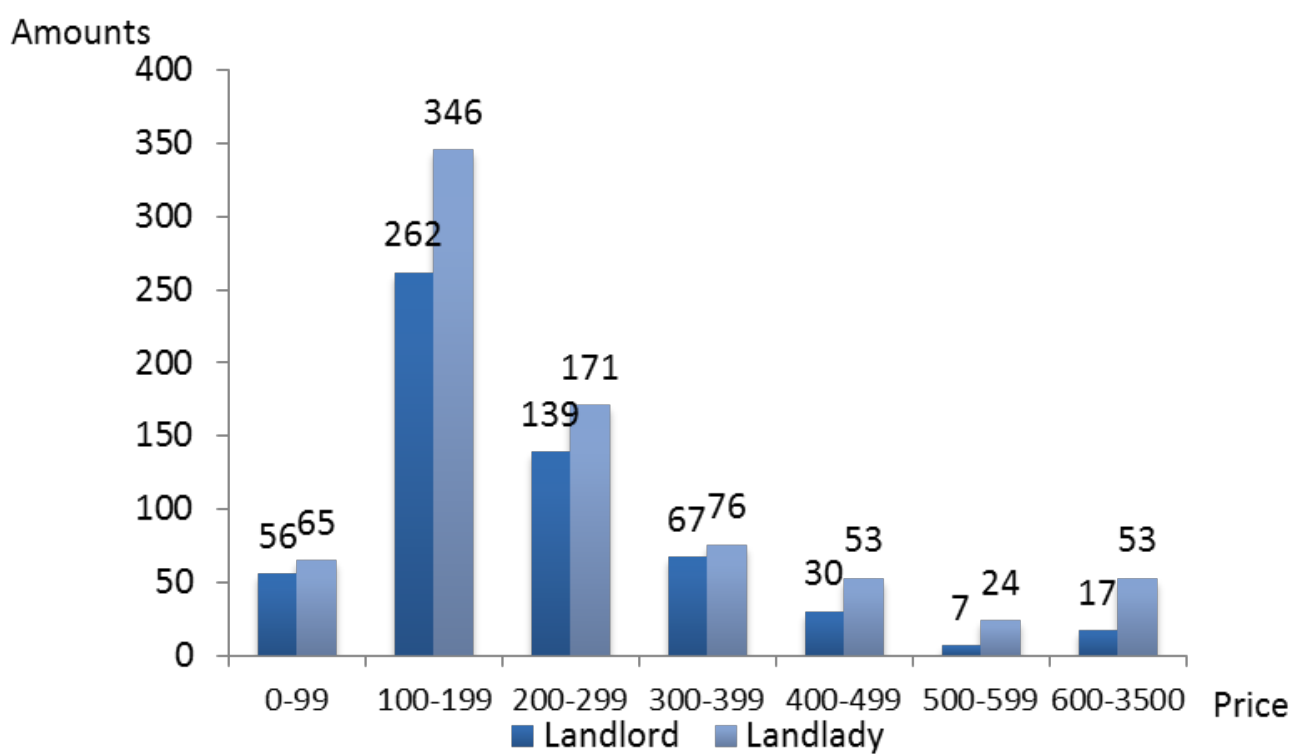

Figure 2 - Housing price distribution in Beijing area on Xiaozhu of landlords and landladies

According to average price shown in Table 3, no-photo houses have lowest price, 114 yuan. Landlords' average price is 243 yuan. Landladies' average price is 272 yuan; family landlords charge 332.2 yuan averagely. If the kids appear on the photo, the landlord can charge more to 559.4 yuan averagely. Only a very small number of landlords did not upload photos. The average price of the house with the owners' photos is much higher than no photos ones; landlords charge $10.74 \%$ lower than landladies; family landlords seems most popular.

Table 3 - Average price of different landlord genders

\begin{tabular}{|c|c|c|c|c|c|c|}
\hline Category & No photo & Male & Female & Family & Unclear & Family with kid(s) \\
\hline Average price & 114 & 243 & 272 & 332 & 346 & 559 \\
\hline
\end{tabular}


Table 4(1) (Table 4, the first vertical column) shows the regression results with STATA on the 497 data in the housing prices and the impact of various factors, we can see that the significant factors are the number of people should live, whole rent or not. According to the results, the price grows when the number of people should live is larger and rent the whole house. The larger number of people indicates that the house is more spacious or has a larger bed or a lot of beds. Whether tenants can enjoy the whole house is also an important factor affecting the rental price-when the tenants do not share the whole house with others, they are willing to pay a higher price. Table 4 - Empirical Results

Table 4 - Empirical Results

\begin{tabular}{|c|c|c|c|c|}
\hline & \multicolumn{2}{|c|}{$\begin{array}{l}\text { Dependent variable: Price } \\
\text { per day }\end{array}$} & \multicolumn{2}{|c|}{$\begin{array}{l}\text { Dependent variable: Price per day } \\
\text { per person }\end{array}$} \\
\hline & (1) & (2) & (3) & (4) \\
\hline Valid & 497 & 1691 & 859 & 832 \\
\hline $\begin{array}{l}\text { Number of } \\
\text { tenants }\end{array}$ & $\begin{array}{c}79.719 * * * \\
(3.68)\end{array}$ & $\begin{array}{c}91.327 * * * \\
(3.09)\end{array}$ & & \\
\hline Whole rental & $\begin{array}{c}3.682 * * * \\
(10.72)\end{array}$ & $\begin{array}{c}96.594^{* * * *} \\
(9.15)\end{array}$ & & \\
\hline Gender & $\begin{array}{l}1.718 \\
(4.94)\end{array}$ & $\begin{array}{c}22.000 * * * \\
(3.87)\end{array}$ & $\begin{array}{c}4.869 * * \\
(1.55)\end{array}$ & $\begin{array}{c}9.55^{* * *} \\
(1.78)\end{array}$ \\
\hline Appreciate rate & $\begin{array}{c}3.616 \\
(10.79)\end{array}$ & & & \\
\hline Cleanness & $\begin{array}{l}-0.229 \\
(2.27)\end{array}$ & & & \\
\hline $\begin{array}{c}\text { Match } \\
\text { description }\end{array}$ & $\begin{array}{l}-0.368 \\
(2.21)\end{array}$ & & & \\
\hline Cost-effective & $\begin{array}{l}-1.55 \\
(2.18)\end{array}$ & & & \\
\hline Safety & $\begin{array}{l}0.503 \\
(2.27)\end{array}$ & & & \\
\hline Traffic & $\begin{array}{l}-0.283 \\
(2.21)\end{array}$ & & & \\
\hline Constant & $\begin{array}{c}-159.04 * * * \\
(48.26)\end{array}$ & $\begin{array}{c}-57.470 * * * \\
(10.9)\end{array}$ & $\begin{array}{c}78.518^{* * *} \\
(3.24)\end{array}$ & $\begin{array}{c}104.115^{* * *} \\
\quad(4.34)\end{array}$ \\
\hline $\begin{array}{c}\text { Number of } \\
\text { tenants }\end{array}$ & Over 1 & Over 1 & 1 & 1 \\
\hline Whole rental & Unknown & Unknown & No & Yes \\
\hline
\end{tabular}

\subsubsection{Will gender affect prices?}

Results of gender regression is not very good in Table 4(1), some variables' impacts on the price are just opposite to expectation, the reason may be (1)the number of sample data with 
evaluation scores is only 497, which is not enough for the empirical research; (2) some ratings are generated by a few comments and a few malicious scores will affect a lot(3) the use of the user's score on behalf of the actual score of the house is not scientific. When the tenants pay more, they want more. When they pay less, they are more likely to give a high score.

Taking into account the above factors, we re-use the 1691 sample data without user evaluation scores, the results are shown in Table 4 (2). The results show that the gender of the owners, the number of people to live, whole rental or not are significant.

The number of people to live is an important factor. We use the total housing prices $\div$ the number of people to live, and then all the houses are divided into 2 groups. They are the whole rent group (832 samples) and shared group (859 samples). Table 4 (4) shows the case of the whole rent, the gender is significant. Table 3 (3) shows the situation of non-full rent, the gender is also significant. Therefore, after the exclusion of living number factor and whole rent factor, the gender will significantly affect the short rental price.

\subsection{Does the discrimination really exist?}

The discrimination means the behavior directed to a particular group of members, which is caused by prejudice awareness. If the price difference comes from the difference in the cost and quality of the product, the difference in price is not discrimination. There is not necessarily discrimination when there is a price difference.

We found that in all the 1691 data, only 6 has no landlord photos; the 6 houses' average rental price is only 114 yuan, well below the average level of 276 yuan. We can assume that the website trying to build trust between the landlord and the tenant by encouraging the landlords to upload photos is indeed feasible to some degree. The possible reason is that (1) the tenants knows the landlords' serious and professional attitude by their behavior of uploading personal photos; (2) to see photos in advance will make them acquaintances.

After comparison we found that the order of gender classification of different landlords' price is: photos are not available $<$ male $<$ female $<$ family $<$ not clear $<$ family has children, but we cannot simply conclude that discrimination exists. The tenant will choose to rent the room seemed to be safest and most reliable. If the landlord is an adult couples with children, they are more appreciated. Gender factors, to a certain extent, are associated with the quality of the house. Landladies are more attractive because the houses of landladies may be tidier. The house of agency landlord has more specialized management, better geographical location and supporting facilities. This information can be caught directly in the house description. 


\section{Is Xiaozhu.com liable for discrimination?}

Xiaozhu can decide what information to collect and publish. They are used to asking the users to give detailed personal information and pictures. This approach does not bring any legal issues according to our law and the photo is an important part of Xiaozhu's rent design.

If Xiaozhu tries to take measures to reduce the impact of the photos for moral considerations, there is something can help, such as:

1. Encourage the communication and understanding between tenants and landlords. If we bind WeChat, QQ or mobile phone text messages with Xiaozhu, then Homeowners and tenants can keep more real-time communication. They will know more about each other and build trust step by step.

2. Act as intermedia and take the responsibility to ensure the interests of both parties. Xiaozhu can investigate regularly to ensure the authenticity and exclude some problematic housing. The excessive participation of intermediaries does not meet the requirements of P2P mode and will increase the operating costs of the site. But the trust between users is hard to be built. To build the trust to Xiaozhu will be easier.

3. Improve the access threshold and keep the user information confidential. The site may ask users to provide their own photos and personal information for smooth operation. But the site should keep the information confidential.

On the one hand, with the progress of society and material living conditions, people will be more open-minded to the society and more willing to believe in others. Online transactions platform will develop more smoothly. On the other hand, the establishment of trust is a long process. If the website does more, we can trust them more and do less.

\section{Reference}

1. Pope, Devin and Justin Sydnor, What's in a Picture? Evidence of Discrimination from Prosper.com, J. Journal of Human Resources, Vol. 46 (2001) 53-92.

2. Benjamin Edelman and Michael Luca, Z. Digital Discrimination: The Case of Airbnb.com. working paper (2014).

3. Yi Fan, Xiaozhu.com and Sharing Economy, J. Shanghai Economy, Vol.2 (2014) 32-33.

4. Pan Yong, Price Discrimination in Online Marketplace, J. Journal of Taiyuan University, Vol.23 (2006) 1-4. 